\title{
Narrative Research on the Professional Development of PE Teachers
}

\author{
Huang Zhou, a, Xin Liü, b \\ ${ }^{1}$ Department of Physical Education, Wuhan University of Technology, Wuhan 430070, Hubei China \\ ${ }^{2}$ School of Education Beijing Sport University, Beijing 100084, China

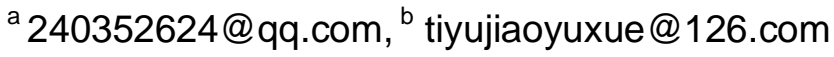

\begin{abstract}
The narrative research is an effective way to study PE teachers' professional development. Study of a super sports teacher education narrative research, firstly, description of the overall impression on him, secondly, refine five topics related to his professional, including: the father and the influence of teachers, job burnout and professional ethics, teaching practice and learning from each other, school leadership and professional development environment and autonomous learning and self-reflection. Finally, based on the education narration of $A$ teacher, the paper analyzed and extracted the main factors that promoted A teacher's professional growth, including family, school leaders, colleagues and students in addition to themselves. Therefore, this paper proposes to promote the professional development of PE teachers by means of external support and internal motivation.
\end{abstract}

Keywords: PE teachers; Professional development; Narrative Research; External support; Intrinsic motivation.

\section{Introduction}

Narration, simply speaking, is to tell a story. It mainly describes individual life and interprets and reconstructs individual life stories, so as to gain the meaning hidden in individual daily life through deep and detailed terrain interpretation and understanding of individual behavior and experience. For teacher professional development, educational narrative research is not only a research method but also a medium of teachers' professional development [1]. Teacher's teaching experience is an important way for their professional development, and this kind of teacher education narrative study, personal, the story of reflective significance for processing and rendering [2,3,4], these will help the teacher to form teaching knowledge and theory of individual personality characteristics, and thus plays an important role in the teachers' professional development.

\section{Research Methods}

This paper adopts the research method of educational narration. The object of educational narration research is A PE teacher of B middle school in $\mathbf{J}$ city (called teacher A). The main materials include in-depth interview, field observation, teachers' work or life notes, and informal interview or oral communication. Through collection and repeated reading of relevant materials and classification and extraction, key themes affecting teacher A's professional growth are sorted out and analyzed and described.

\section{Results and Analysis}

\subsection{The Theme Affecting Teacher A's Professional Growth}

\subsubsection{The Influence of Fathers and Teachers}

When talking about the person who has a deep influence on teacher A in the process of becoming A special grade teacher, teacher A first mentioned the family influence. From A teacher in the description of his father, which can see that he admire, respect and love his father. At the same time, I can also feel the subtle influence of teacher A's father on his practice, which plays an important role in the cultivation of teacher A's educational belief. Secondly, teacher A mentioned the influence of 
teachers. He believed that teachers, including leaders and colleagues, are important "collaborators" in his career. Their interpersonal relationship and communication mode directly affect teacher A's professional identity and professional development.

\subsubsection{Burnout and Work Ethic}

Physical education teachers' job burnout will go through three processes of emotional exhaustion, dehumanization and decreased sense of achievement. Once they go through these three processes, physical education teachers will have frustration in life and work, which will easily lead to resignation, absenteeism and decreased work enthusiasm [5]. Therefore, it is very important to help teachers get through or avoid burnout in their career.

In teacher A's narration, he said that "I wanted to resign in 1992 because the status of teachers was low", "I didn't earn money" and "I also felt that I was poor in knowledge, so I was poor in knowledge and couldn't teach". This is the situation of job burnout in the process of teacher A's professional development. He elaborated from the aspects of low status, low income, insufficient ability and low sense of achievement of teachers. In this case, teacher A proposed the idea of resignation. After that, with the encouragement and guidance of his father and teachers, teacher A successfully got through job burnout, formed good professional ethics, and love students and education.

\subsubsection{Teaching Practice and Teaching Benefit Each Other}

Physical education teaching practice is the most direct way for physical education teachers to gain professional growth, and the positioning of teaching objectives is the basis for teachers to carry out teaching. Teacher A believes that "running and jumping are only explicit objectives, while physical education teaching has many implicit objectives, which are to improve students' mind and body. In this aspect, teachers should further strengthen... ". In my opinion, teacher A's teaching style and students' PE learning state are directly related to teacher A's teaching objectives. In addition, teacher A often instructs young teachers to design course content flexibly, teach students to learn and let students understand, which not only reflects teacher A's summary of teaching experience, but also shows his requirements for new teachers. At the same time, in teaching, teacher $\mathrm{A}$ is also good at communicating with students, listening to students, observing students, and learning from them.

\subsubsection{School Leadership and Professional Growth Environment}

Teacher A pointed out in the statement that the school leaders attached great importance to physical education and showed great care for him, which promoted teacher A's progress in teaching and professional growth. In addition to school leaders, the interpersonal relationship between PE teachers in teacher A's school is also very harmonious. When describing the interpersonal relationship between PE teachers and the professional development platform provided by the school, teacher A expresses more satisfaction. Good interpersonal relationship and diversified professional development platform meet the needs and wishes of teacher A in his professional growth, enabling teacher A to "focus on teaching". At the same time, teacher A is not only striving for personal development, but also learning humbly for the better development of students.

\subsubsection{Self-study and Self-reflection}

Autonomous learning ability is the ability manifested and formed in the process of individual learning from "others" to "autonomy" [6]. Reflection is generally regarded as a way of spiritual selfactivity and introspection, and its essence is critical thinking with reflection and inquiry [7]. Teacher A mentioned "study and reflection" many times in the narrative, he said" teachers should think more, think more about why", "we should borrow the wisdom of others, do the things what we understand, confuse things out, come out the successful experience, so as to obtain the development", "if the internal cause does not work, then the external cause is not strong enough to do". It can be seen from the statement that teacher A attaches great importance to independent learning and self-reflection in teaching practice and daily life, and gains teaching and working experience from it, thus promoting his own professional development. 


\subsection{Conclusions of Teacher A's Education Narrative Research}

From the overall perspective of teacher A's education narrative, in the process of teacher A's professional growth, factors include family, colleagues, school leaders and students as well as himself. These factors play an important practical role for teacher A to grow into a special grade PE teacher and form his own unique educational goals and teaching ideas.

\section{Enlightenment to the Professional Development of PE Teachers}

\subsection{External Support: Build a Harmonious and Symbiotic Professional Development Environment}

Professional development environment includes spiritual environment, institutional environment, material environment, etc. A good professional development environment is a tangible boost for PE teachers to gain effective professional growth. From the perspective of school level, first of all, leaders should improve their care and attention to PE teachers, so that PE teachers can feel valued and needed. Secondly, we should construct a reasonable professional development system for PE teachers. Finally, schools should attach importance to team evaluation of PE teachers and promote the formation of efficient professional development community. Through the guidance of team evaluation, the school should help teachers form the idea that personal progress cannot be separated from excellent teams, so that the PE teachers can form a team culture of mutual help, cooperation and selfless dedication, and truly implement the effect of the PE teachers' professional development community, so as to effectively improve the PE teachers' professional development.

\subsection{Intrinsic Motivation: Self-study and Self-reflection}

External support provides a series of spiritual, policy and team support for the professional development of PE teachers, which is a necessary condition for physical education teachers for professional development. And the intrinsic motivation urges the PE teachers to produce the demand of professional development in the favorable professional development environment, and it is the source of PE teachers' professional development. Of course it is the core and key of PE teachers' professional growth. Teacher A repeatedly emphasizes the importance of independent learning in his narration. To achieve good professional growth, independent learning is the key. At the same time, "I reflect on myself three times a day", "Review the old and learn the new", keep the habit of reflection in the process of continuous learning can help PE teachers clarify their advantages and disadvantages in curriculum implementation, curriculum evaluation, teacher-student relationship and other aspects.

\section{Summary}

The professional growth of PE teachers in middle schools not only affects the personal quality of PE teachers, but also relates to the development and implementation of PE courses in middle schools. Therefore, the professional development of PE teachers in middle schools should be the focus of researchers. At the same time, how to use effective research methods to explore the path of physical education teachers' professional development, to solve the difficulties in physical education teachers' professional development, will be our responsibility and obligation as a teacher education researchers.

\section{References}

[1]. C. Conle. Narrative Inquiry: Research Tool and Medium for Professional Development [J]. European Journal of Teacher Education,2000,3(1):49.

[2]. Clandinin, D. J., \& Connelly, F. M. Narrative inquiry[M]. San Francisco: Jossey-Bass,2000.

[3]. Jalongo, M. R., \& Isenbery, J. P. Teacher Stories: From Personal Narrative to Professional Insight [M]. San Francisco: Jossey-Bass, 1995:4. 
[4]. Goodson, I. "Trendy Theory" and Teacher Professionalism. In A. Hargreaves \& R. Evans (Eds). Beyond Educational Reform: Bringing Teachers Back in[M]. Buckingham, England: Open University Press, 1997:29-43.

[5]. LIMing Cao. Study on occupational burnout of PE teachers in middle school under the background of PE curriculum reform [J]. Journal of Wuhan physical education institute, 2006, 40 (3): 106-108.

[6]. Chang Liu. Study on students' independent learning [J]. Education research,2014(7):131-135.

[7]. Xiujuan Wu, Hao Zhang, Changqing Ni. Deep learning based on reflection: connotation and process [J]. Research on audio-visual education,2014(12):23-28+33. 